Revista Internacional de Apoyo a lalnclusión, Logopedia, Sociedad y Multiculturalidad.

Volumen 5, Número 2, Junio 2019, ISSN: 2387-0907.DOI: https://dx.doi.org/10.17561/riai.v5.n2.5

\title{
Aceitação dos pais para o transtorno do espectro autista do filho
}

(La aceptación de los padres para el trastorno del espectro autista del hijo)

\author{
Aldylayne Elen Oliveira Duarte \\ Universidade Uninassau, João Pessoa (Brasil) \\ aldylayneduarte@gmail.com \\ Páginas: 53-63
}

Fecha recepción: 01-02-2019

Fecha aceptación: 20-05-2019

\section{Resumo.}

O presente trabalho apresenta quais as reações dos pais frente ao diagnóstico do Transtorno do Espectro Autista (TEA), bem como as possíveis dificuldades em aceitar um filho com este Transtorno, e a importância dos pais no desenvolvimento do seu filho. 0 método foi a Revisão bibliográfica Narrativa da literatura através de buscas nos bancos de dados: Google Acadêmico e Scielo, sendo 62 artigos, 2 dissertações, 3 livros e 2 teses. Foram identificadas as dificuldades em aceitar um filho com TEA em duas vertentes, uma pessoal e outra social. A pessoal diz respeito à quebra da idealização do filho perfeito e as demandas cansativas que a criança com TEA apresenta. As questões ressaltam o preconceito ao diferente, as poucas informações recebidas sobre 0 transtorno e escassas assistências em órgãos públicos ao transtorno e aos pais. Conclui-se que é imprescindível que os pais sejam acompanhados após o diagnóstico do filho, pois eles serão os responsáveis pelo desenvolvimento saudável da criança, a quem ela precisará para um bom prognóstico como também os profissionais estejam preparados para atender estas famílias que muito sofrem em buscas de respostas e de um diagnóstico com rapidez para seu filho.

Palavras-chave: autismo; pais; aceitação

\begin{abstract}
.
This research intends to show which the parent's reactions in relation with Autistic Spectrum Disorder (ASD), and the difficulties to accept a son with this kind of Disorder, and the relevance of the parents in the development of their son. The method was choosing with a bibliographical review of the narrative literature. In order to make this research we made searches in databases: academic Google and Scielo, 62 papers, 2 dissertations, 3 books and 2 theses. We identified the difficulties to accept sons with ASD are divided in two strands, personal and the social. The personal refers to the break of the idealization of the perfect son and the tiring demands presented by the child with ASD. The social questions concern to the prejudice to the different, the lack of information received about the disorder and the lack of assistance in public agencies to the disorder and to the parents. Our conclusion demonstrates that is very important that the parents be accompanied after the child's diagnosis, because they also fit the diagnosis. They are responsible for the healthy child development, and the child will need them for a good prognosis.
\end{abstract}

Key words: autism; parents; acceptance 


\section{1.-Introdução.}

O Transtorno do Espectro Autista (TEA) é uma perturbação que acomete 0 desenvolvimento da criança, prejudicando e colocando algumas dificuldades a educação e integração social do sujeito (Ferreira, 2011). O autismo tem como característica padrões de comportamento repetitivos e estereotipados, incluindo inflexibilidade a mudanças, permanência a rotinas, e manifestações de comportamento como: Déficits na interação e comunicação social (Gadia, Tuchman e Rotta, 2004).

As manifestações do transtorno ocorrem de formas e graus distintos para cada caso tanto no que diz respeito à comunicação verbal e não verbal. Uns não apresentam habilidades para se comunicar, outras possuem habilidades imaturas que são: Ecolalia, jargões, entonações monótonas. Aqueles com capacidade de se comunicar pode haver déficits em iniciar ou manter a conversação (Gadia, Tuchman e Rotta, 2004).

O transtorno Autista também pode ser entendido como uma vivência do estado mental com insuficientes habilidades em diferenciar os estímulos provenientes de dentro e fora do seu corpo, como também a dificuldade na construção de manifestar e representar emoções (Bosa e Callias, 2000).

Os pais estão preparando-se física e psicologicamente para receber o filho "ideal", certamente estes, não estarão capacitados para receber alguma "imperfeição" que este possa vir a apresentar. Habitualmente, os pais não recebem orientações quanto a possibilidade do anuncio de um transtorno, não cogitam seu filho com nenhum tipo de deficiência que poderá impossibilitá-lo de realizar todos os desejos que seus pais antes estavam a planejar, quando isto acontece, eles passam por um estágio de luto pela vinda do filho não esperado (Sassi, 2013).

Quando a chegada do filho esperado é acompanhada com algum transtorno, assistese, dolorosamente, a um rigoroso desafio para os pais, os quais não imaginavam sua criança pudesse apresentar algum tipo de malformação, caracterizando assim uma ameaça às suas crenças e expectativas sobre o bebê que até então havia sido, por todo o tempo, fantasiado e idealizado antes mesmo do seu nascimento (Sassi, 2013).

Desta forma esta pesquisa buscou encontrar quais as possíveis dificuldades de os pais aceitarem um filho com transtorno do espectro autista, bem como quais as reações dos pais frente ao diagnóstico do Transtorno do Espectro Autista do filho e a importância da aceitação deles, baseando as informações em artigos científicos. Foram levantadas as hipóteses de que as expectativas sobre o filho "perfeito" podem dificultar a aceitação do filho com TEA, sendo a aceitação a peça fundamental para 0 desenvolvimento saudável da criança. 
A família é o primeiro grupo social que o indivíduo participa, eles são os principais responsáveis pelo desenvolvimento de sua criança (Maia Filho, et al., 2016). Com isso, sabe-se a necessidade do acolhimento dos pais para com a criança, aqui falando em especial com transtorno do espectro autista. $\mathrm{O}$ amor, cuidado e proteção destinados a criança, aliados a busca dos tratamentos e informações inerentes ao Transtorno do espectro Autista possibilitarão uma melhor adaptação da família, pois estes precisaram lidar com esta situação por toda a vida, pois se trata de uma doença crônica.

Alertar a população quanto a estas questões poderá ajudar pais que se encontrem nesta situação. A pesquisa favorecerá uma expansão de informações inerentes 0 tema em questão, o que possibilita outros profissionais a atentarem sobre 0 assunto, podendo ampliar outras pesquisas nesta área.

\section{2.-Desenvolvimento.}

\section{1.-Autismo.}

Leo Kanner Psiquiatra austríaco em 1943 descreveu inicialmente o autismo baseado em casos de 11 crianças que foram acompanhadas por ele as quais apresentavam prejuízos nas áreas de Relações sociais, comportamento e comunicação (Lemos, et al., 2016).

Com a nova classificação para transtornos mentais no Manual Diagnóstico e Estatístico de Transtornos mentais (DSM-V) APA (2014), os Transtornos Globais do Desenvolvimento - os quais incluem o Autismo, Transtorno Desintegrativo da Infância, as Síndromes de Asperger e Rett - foram acoplados em uma só nomenclatura e unidos por um único diagnóstico, agora denominado de Transtornos do Espectro Autista (Araújo e Lofuto Neto, 2014).

Segundo o DSM- V APA (2014) publicado pela Associação Psiquiátrica Americana, as principais características do Transtorno do espectro autistas são identificadas no prejuízo persistente na comunicação social recíproca e interação social (Critério A do DSM-V), padrões de comportamentos, interesses ou atividades restritos e repetitivos (Critério B do DSM-V), sintomas estes presentes no início da infância limitando e prejudicado a rotina diária. Os níveis de gravidade variam em 3: Nível 1, no qual necessita-se de apoio; nível 2 que exige apoio substancial e Nível 3 exigindo apoio muito substancial.

A mudança ocorreu por refletir a partir de um olhar científico de que aqueles transtornos de fato são uma mesma condição manifestada em dois grupos de sintomas: Déficit na comunicação e interação social e padrões de comportamentos, interesses e atividades restritos e repetitivos (Araújo e Lofuto Neto, 2014).

O transtorno se apresenta com vários comportamentos que não aparecem na mesma forma, momentos e intensidades, são caracterizados por uma tríade que comprometem: 0 desenvolvimento de interação social; comunicação e 
comportamentos estereotipados. 0 autismo não é diagnosticado através de exame de sangue ou exames cerebrais, para identificá-lo os médicos observam os comportamentos como também a história do sujeito (Silva, 2009).

Lemos et al. (2016), fala da importância de mencionar a existência de fatores genéticos ou neurobiológicos presentes no Transtorno do Espectro Autista (TEA), indicado através de estudos em famílias com membros que apresentam esse transtorno. De acordo com Mota et al. (2011) Há um pouco mais de seis décadas 0 Transtorno do espectro autista vem sendo estudado cientificamente. A curiosidade sobre as características diagnósticas, definições e etiologia têm instigado pesquisadores a investigar a respeito deste transtorno. Antes dos 3 (três) anos de idade já é possível observar alguns aspectos relacionados ao autismo, a criança geralmente permanece distante do contato social (Leandro e Lopes, 2017).

Pouco se sabe sobre as causas do autismo, estudiosos buscam o que ocasiona este transtorno e alguns fatores foram observados quanto a fatores que podem ser predisposições: rubéola na mãe, meningite, exposição a componentes químicos, encefalite, fenilcetonúria (Santos, 2008). As definições de autismo foram se modificando a partir de pesquisas científicas que descobriram diversas etiologias, graus e especificidades, passando a não mais ser considerado um único quadro, mas agora uma síndrome (Schmidt e Bosa, 2003).

O Isolamento é um dado característico desde os primeiros anos de vida em crianças com TEA, assim havendo uma dificuldade em estabelecer relações pessoais e sociais, como também o déficit no vínculo materno (Ribeiro, 2012). Fonseca e Missel (2014) comentam que quando surgiram as primeiras associações para o transtorno do espectro autista no Brasil, poucos eram os profissionais que conheciam acerca do mesmo. Hoje, apesar de o autismo ser mais conhecido, ele ainda pode surpreender pelas inúmeras características que apresenta.

A criança autista geralmente não nasce com complicações, possui aumento de peso e cresce, porém, começa a apresentar falta de interesse pelo meio, prefere quase sempre isolar-se, 0 olhar nos olhos não acontece, evita contatos. $O$ interesse no brincar está voltado para objetos fixos sem muitas opções, de forma obsessiva, como também possui dificuldade em variação alimentar (Rodrigues, Fonseca e Silva, 2000).

Embora algumas crianças não evidenciem dificuldades na linguagem, é preciso entender que estas também necessitam de atenção especial em algumas questões. Crianças autistas possuem dificuldades em compreender um discurso abstrato, como conto de metáforas (Bosa, 2006). Não há um tempo preciso de quando iniciar 0 tratamento, 0 ideal seria antes dos três anos de idade, mas sabem-se que 0 quanto antes houver 0 diagnóstico e iniciar 0 tratamento, as chances de evolução são significativas (Fonseca e Missel, 2014). O tratamento para o TEA vai depender do comprometimento que a criança apresenta, cada caso é uma questão singular (Bosa, 2006). 
O acompanhamento dos primeiro marcos do desenvolvimento da criança é muito importante para se diagnosticar qualquer alteração apresentada na primeira infância. Aqui falando do autismo estes dados são mais relevantes, levando em consideração que quanto antes for notado alguma disfunção, maiores serão as chances de correção (Gaiato, Reveles e Silva, 2012).

\section{2.-Família e Autismo.}

O sistema familiar tem importante papel na formação dos sujeitos, sendo determinante na constituição da personalidade, como também influência no comportamento do indivíduo por meio de ensinamentos e ações provenientes no seio familiar (Pratta e Santos, 2007). Assim, Rodrigues, Sobrinho e Da Silva (2000) descreve a família sendo a protagonista no que tange a responsabilidade de cuidar, proteger, e prover de ensinamentos para o indivíduo conviver em sociedade.

Os casais antes mesmo da gravidez, já pensam como será a chegada de um filho no seio familiar, e cogitam as suas possibilidades, pensando em como seria física e intelectualmente, porém, geralmente não há menção de ocasionalmente vir um filho com deficiência. Sassi (2013) relata ser de uma verdadeira experiência única a chegada do filho trazendo consigo um misto de sentimentos que envolvem curiosidade, ânsia até seu nascimento e expectativas que vão para além do real. Com isso, desenvolve-se a conexão entre filhos e pais quando estes já projetam suas fantasias nos filhos.

\section{3.-Método.}

Este estudo caracteriza-se como exploratório, sendo o procedimento técnico uma pesquisa bibliográfica narrativa de abordagem qualitativa a qual se propõe buscar 0 máximo de informações relevantes sobre o problema em pauta, como também unir os dados importantes encontrados na literatura que enfoquem e embasem as questões levantadas, buscando aprofunda-se no tema e mostrar sua relevância de forma coerente e evidente. Para Rother (2007) a Pesquisa Bibliográfica narrativa caracteriza-se como uma busca ampla e adequada para atender o tema em questão, descrevendo e discutindo. Esta pesquisa se dá sob o viés teórico ou contextual.

Pesquisa bibliográfica configura-se como um conjunto em que se ordenam os procedimentos a fim de buscar soluções, focalizando o objeto de estudo. (Lima e Mioto, 2007). A pesquisa Bibliográfica caracteriza-se um procedimento metodológico capaz de produzir conhecimentos científicos, assim possibilitando explorar temas poucos comentados, como também sobre a postulação de hipóteses, que possivelmente serão úteis para fomentar novas pesquisas (Lima e Mioto, 2007).

A coleta de dados realizou-se a partir de buscas no: Google Acadêmico e Scielo tendo como critérios de seleção arcabouços teóricos para construção da explicação do tema em pauta, que trouxesse de forma explícita as questões levantadas entre 2000 a 2017, mostrando alguns dados, classificações e explanações sobre TEA; família; a família enfrentando o TEA, e a importância dos pais no desenvolvimento 
dos filhos com TEA. As palavras chaves utilizadas para a busca dos arquivos foram: autismo, aceitação e pais. Os dados foram organizados por meio de fichamento. Os materiais coletados foram: 4 livros, 2 Teses, 2 Dissertações e 54 Artigos encontrados em revistas científicas, totalizando 62 materiais.

\section{4- Discussões.}

Diante da proposta desta pesquisa em responder quais as possíveis dificuldades por parte dos pais em aceitar um filho com Transtorno do espectro autista, foi possível responder o problema da pesquisa, assim como os objetivos lançados, mostrando que há dificuldade em aceitar um filho com transtorno do espectro autista, e denota que estas dificuldades na aceitação se relacionam a variados fatores, divididas em duas vertentes: Dificuldades de aceitação por questões pessoais e dificuldades de aceitação por questões sociais. Abordaremos primeiro as dificuldades pessoais e depois as sociais.

Assim, sobre as Dificuldades de aceitação por questões pessoais observa-se que quando recebe a notícia da deficiência, este momento torna-se um desafio na aceitação no que tange a quebra da idealização feita pelos pais desde o momento do anúncio da gravidez. Fiamenghijr e Messa (2007) falam que a criança já ocupa um espaço determinado pelas expectativas dos pais geradas sobre ela.

Sassi (2013) Relata que a chegada de um bebê é uma experiência única e traz consigo um misto de sentimentos: Ansiedade, curiosidade e idealizações para além do real, projetando suas fantasias no filho, Vendrusculo (2014) igualmente descreve que desde 0 anúncio até a chegada do bebê os pais planejam e sonham o futuro do seu bebê.

Outro fato que acomete os pais físicos e emocionalmente diz respeito ao tratamento do filho, recolhemos muitos dados no que se refere às muitas demandas que 0 Transtorno do Espectro autista traz assim precisando a família se readaptar a esta nova realidade, porém com o passar dos dias, a sobrecarga acaba por acarretar em fragilidade física e emocional, fazendo com que o sistema se modifique, a família muitas vezes deixem de se cuidar, pois sua atenção e dedicação estão voltadas para o filho, como coloca Assumpção Jr e Sprovieri (2001) que as famílias passam muito tempo em instituições, permanecendo longos períodos da semana fora do lar, gerando assim uma sobrecarga e desestabilizando o sistema. Schimidt e Bosa, (2007) em uma pesquisa falam que mães com filhos autistas não trabalham fora ficando seu dever somente cuidar do filho.

Monte e Pinto (2015) apontam que as famílias com filhos autistas apresentam estresse agudo pela carga de cuidados que o filho necessita, precisando estar em médicos, terapias. As mães apresentam estados depressivos pela sobrecarga em geral, como também pela falta de apoio e gastos destinados aos tratamentos (Ribeiro, 2012). É importante mencionar que não só a criança está acometida como 0 TEA sofre, mas toda a família que convive com ela, devido a carga de assistência no intuito de melhor atender o filho. 
Outro dado faz menção à inabilidade de contato que a criança com TEA apresenta esta característica, sendo uma das principais apresentadas pelo TEA: 0 déficit de interação e comunicação social do Autista faz também com que dificulte 0 relacionamento com os pais, pois eles muitas vezes não entendem o que 0 filho pede ou tenta expressar, como coloca Ribeiro, (2012), e igualmente cita Balestro e Fernandes (2012) que obtiveram como resultado dos questionários destinados as dificuldades encontradas pelos pais de autistas, e colheram como resultado 0 sentimento angústia sentida pela família por não entender quando 0 filho se comunica com eles.

Com relação às Dificuldades de aceitação por questões sociais: Umas das dificuldades também encontradas diz respeito a falta de informações acerca do Transtorno confirmadas por Silva (2009) dizendo que por receber poucas informações sobre a deficiência do filho acarreta na desestabilização do sistema familiar por ter que enfrentar a nova realidade. Além do do luto que a família está elaborando pela vinda do filho não esperado, agora precisam lidar com várias demandas que a criança apresenta em decorrência do Transtorno, das quais poucos conhecem.

A falta de informações, proveniente dos postos de atendimento a este público, nas obras científicas encontradas aparecem escassas. Este fato pode ocasionar dúvidas nestes pais, por não entenderem o funcionamento psíquico do seu filho, como também quais suas habilidades, e a esperança por um prognóstico que venha apresentar sucesso evolutivo.

Encontramos um trabalho feito por Roncon (2012) que apresentou um caso clinico em que a família de uma criança autista recebeu apoio psico-social em um grupo terapêutico, e sinalizou a grande satisfação dos pais pelo apoio, sentindo-se acolhidos e mais ativos no processo de desenvolvimento dos seus filhos, pois através dessa dinâmica com a instituição, pode entender mais sobre os aspectos do transtorno, bem como usar esse espaço para ser um momento deles, que também precisam ser ouvidos e compreendidos.

Com isso podemos entrar enfatizar a importância da assistência aos pais, um trabalho que esteja pronto para atender suas angústias e inquietações, como orientar no manejo do dia a dia com o filho. Observa-se também a necessidade de integrar instituições: Escola, Terapeutas em geral, pais para melhor serem agentes potencializadores do prognóstico da criança.

Outro dado encontrado diz respeito ao preconceito destinado ao transtorno, pois o Autista apresenta estereotipias, e inabilidade em contato social, em função disso a família começa a isolar-se do meio social, evitando expressões ou possíveis verbalizações da sociedade que possam atingir seu filho, relatado por Ribeiro (2015).

A questão do futuro do filho, é um aspecto que inquieta os pais, por pensarem no momento em que eles não estiverem mais presentes para provê-los de cuidado, apontando por Oliveira et al. (2015) quando fala da preocupação dos pais em não 
saber se haverá suporte em entidades públicas para ajudá-los no desenvolvimento e passar das fases do seu filho.

A psicologia pode trabalhar os aspectos do Transtorno do Espectro Autista, como na assistência a estas famílias, sejam nos âmbitos escolares, clínicos, ou serviços de assistência: NASF, CRAS, CREAS. É preciso estar buscando se apropriar do TEA, para assim poder dispor de um bom prognóstico, entendendo que os pais são agentes desta evolução, mas eles também estarão precisando de serem assistidos, pois são eles quem recebem toda a carga que este Transtorno apresenta. Quanto ao preconceito direcionando ao diferente, é um cenário muito debatido, porém ainda presente em nosso meio, entendendo o ser humano enquanto um indivíduo BIOPSICO-SOCIAL, leva-se em consideração todos os aspectos que possam infligir sua integridade.

Hoje, as redes socais estão muito presentes, pois estamos na era da tecnologia é um meio para propagar campanhas e sinalizações a respeito do que estes preconceitos podem causa em danos psicológicos. Nós enquanto profissionais de psicologia devemos ter o olhar amplo para lidar com as questões que chegarão até nos.

\section{5.-Conclusão.}

Conclui-se que encontramos o que foi proposto como objetivo deste trabalho, identificar quais as dificuldades em aceitar um filho com Transtorno do espectro autista, as reações dos pais frente ao diagnóstico, e a necessidade da aceitação deles para com os filhos através de dados científicos, e as literaturas apontam que os pais no primeiro momento vivem o luto pela vinda do filho não esperado, e por vezes adiam o tratamento da criança por boicotar os sintomas e diagnóstico do TEA, eles estavam preparados para receber o filho "ideal", fantasiado e idealizado com todas as potencialidades invictas, e este não chegando eles passam por um estado de negação da realidade; posteriormente, quando se reconhecem e aceitam a busca pelo tratamento, os pais enfrentam outras dificuldades, a exemplo da rotina em centros especializados, e o cotidiano da família, volta-se para atender as demandas do filho. Estas questões acarretam em estresse por parte dos pais, pela sobrecarga que o dia a dia traz.

Também foi possível observar que a escassez na assistência ao transtorno em órgãos públicos é algo que preocupa e fragiliza os pais, pois muitos não sabem manejar as atitudes do filho, e o fator futuro está em jogo, pois os pais já pensam 0 momento em que eles não mais poderão ser os provedores de cuidado. É de grande valia que possam ser publicadas obras que discorram sobre os manejos da família com filho autista nas fases no seu desenvolvimento, bem como órgãos públicos e profissionais da área estejam prontos para atender essas famílias, sendo capazes de orientarem estes pais quanto suas inquietudes e questionamentos que possam surgir. 
Este estudo possibilitou a necessidade de sensibilizar o olhar para os pais que estão enfrentando estas questões, entendendo que eles igualmente precisam ser acompanhados para melhor entender, atender e conviver com o Transtorno do Espectro Autista. Como desdobramentos futuros, em uma possibilidade de PósGraduação, há um pensamento em pesquisar mais sobre estatísticas que possam apresentar dados sobre como se dá a assistência a esses pais, qual população que é favorecida desses benefícios de informações, e se posteriormente essas famílias continuam sendo acompanhadas. Pois a realização desse trabalho o tempo foi curto, impossibilitando um aprofundamento nas questões probabilísticas.

É imprescindível que os pais elaborem essa nova demanda, e estejam dispostos para lutar pelo tratamento do seu filho, acolher e conceber carinho e ensinamentos, pois eles são os principais responsáveis por seu desenvolvimento. Após a notificação de um transtorno, todo o seu cotidiano irá sofrer modificações, quebrando assim rotinas e afazeres dos membros em geral. Contudo, haverá uma contribuição para 0 campo da psicologia, no âmbito clinico e social, a percepção de que enquanto profissionais, precisa-se estar atento para estas demandas que chegam, estando dispostos a atender esta família que passa por momentos difíceis, podendo então acolher e possibilitar informações inerentes ao Transtorno, onde como a literatura apresentou, muitos estão a mercê de uma realidade a qual não sabem lidar, nem compreender, tornando assim mais uma barreira entre famílias, filho, e o TEA.

\section{Referências.}

Araújo, A.C., Lofuto, F.A. (2014 ). Nova Classificação Americana Para os Transtornos Mentais - 0 DSM-5. Revista Brasileira de Terapia Comportamental e Cognitiva. Vol. XVI, no. 1, $67 \quad$ - 82. Disponível em:<http://pepsic.bvsalud.org/scielo.php?script=sci_arttext\&pid=S151755452014000100007>

Associação Americana De Psiquiatria. DSM-V. (2014). Manual diagnóstico e estatístico de transtornos mentais. Trad: Marina Inês do Nascimento - 5.ed. rev. - Porto Alegre: Artmed.

Assumpção J.F., Pimentel, A.C.M. (2013). Autismo infantil. Revista Brasileira de Psiquiatria. Minas Gerais. Disponível em: http://www.scielo.br/scielo.php?script=sci_arttext\&pid=S151644462000000600010.

Balestro, J.I., Fernandes, F.D.M. (2012). Questionário sobre dificuldades comunicativas percebidas por pais de crianças do espectro autista. Rev. Soc. Bra.fonoaudiol. v.17 N.3, p. 279-286, São Paulo. Disponível em: $<$ http://www.scielo.br/pdf/rsbf/v17n3/08.pdf>

Bosa, C.A., Callias, M. (2000). Autismo: breve revisão de diferentes abordagens. Psicologia: reflexão e crítica. Porto Alegre. Vol. 13, n. 1 p. 167- 
177. Disponível em: <http://www.scielo.br/scielo.php?pid=S010279722000000100017\&script=sci_abstract\&tlng=pt>

Bosa, C.A. (2006). Autismo: intervenções psicoeducacionais. Revista brasileira de psiquiatria $=$ Brazilian journal of psychiatry. Vol. 28, supl. 1, p. 47-53, 2006. Disponível em: $<$ http://www.scielo.br/scielo.php?pid=S151644462006000500007\&script=sci abstract\&tlng=pt>.

Ferreira, I.M.D.M. (2011). Uma criança com perturbação do transtorno do espectro autista: um estudo de caso. Tese (Mestrado em educação). Castelo Branco: Instituto Politécnico de Castelo Branco. Disponível em:<https://repositorio.ipcb.pt/bitstream/10400.11/700/1/Tese_Isabel_Ferreira .pdf>.

Fiamenghi J.G.A., Messa, A.A. (2007). Pais, filhos e deficiências: Estudo sobre as relações familiares. Psicologia Ciência e profissão. São Paulo, 2007. Disponível em:<http://www.scielo.br/scielo.php?script=sci_arttext\&pid=S141498932007000200006\&lng=en\&nrm=iso\&tlng=pt>.

Fonseca, S.A, Missel, A. (2014). Autismo: Auxílio ao desenvolvimento antecipadamente. Revista pós graduação: Desafios contemporâneos. V 1, n 1, p 83/99, Cachoerinha RS. Disponível em:<http://ojs.cesuca.edu.br/index.php/revposgraduacao/article/view/622>.

Gadia, C.A, Tuchman, R., Rotta, N.T. (2004). Autismo e doenças invasivas de desenvolvimento. Jornal de pediatria, v. 80, n. 2, p. 83-94. Disponível em:<http://www.scielo.br/scielo.php?pid=S002175572004000300011\&script= sci_abstract\&tlng=pt>.

Gaiato, M.B., Reveles, L.T., Silva, A.B.B. (2012). Mundo singular: entenda o autismo. Rio de Janeiro: Objetiva.

Leandro, J.A., Lopes, B.A. (2017). Carta de mães e pais de autistas ao Jornal do Brasil na década de 1980. Interface- comunicação, saúde e educação. Ponta Grossa - Paraná. Disponível em:<http://www.scielo.br/pdf/icse/2017nahead/1807-5762-icse-1807576220160140.pdf>.

Lemos, E.L.M.D. et al. (2016). Concepção de pais e professores sobre a inclusão de crianças autistas. Universidade Federal da Paraíba. Artigo Fractal: Revista de Psicologia, v. 28, n. 3, p. 351-361, set.-dez. João Pessoa, Paraíba, Brasil. Disponível em:<http://www.scielo.br/scielo.php?pid=S198402922016000300351\&script=sci_abstract\&tlng=pt>. 
Lima, T.C.S.D., Mioto, R.C.T. (2007). Procedimentos metodológicos na construção do conhecimento científico: a pesquisa bibliográfica. Revista Katálysis, v. 10. Disponível em:<http://www.scielo.br/pdf/rk/v10nspe/a0410spe>.

Maia, A., Nogueira, L.A.M.N., Silva, K.C.O., Santiago, R.F. (2016). A importância da família no cuidado da criança autista. Revista Saúde em Foco. Teresina, v. 3, n. $1, \quad$ art. $1, \quad$ p. 66-83, jan.jun. Disponível em:<http://www4.fsanet.com.br/revista/index.php/saudeemfoco/article/view/71 $9>$.

Mota, A.C.W., Cruz, R.M., Viera, M.L. (2011). Desenvolvimento e adaptabilidade de pessoas com transtorno autista na perspectiva evolucionista. Revista Brasileira Crescimento e Desenvolvimento humano. v21 n02. São Paulo. Disponível em:<http://pepsic.bvsalud.org/scielo.php?script=sci_arttext\&pid=S0104$12822011000200021>$.

Ribeiro, M.F.M. (2012). Aprendendo a ser mãe de uma criança autista. Estudos Goiânia, v. 39, n. 4, p. 579-589, out./dez. Disponível em:<http://revistas.pucgoias.edu.br/index.php/estudos/article/viewFile/2670/1 632>.

Rodrigues, M.S.P., Sobrinho, E.H.G., Da Silva, R.M. (2000). A família e sua importância na formação do cidadão. Família, Saúde e Desenvolvimento, v. 2, n. 2. Disponível em:< file:///C:/Users/Aldylayne/Downloads/4934-11182-1$\mathrm{PB} \% 20(1)$.pdf>.

Santos, A.M.T. (2008). Autismo: Desafio na alfabetização e convívio escolar. São Paulo: Atlas. Disponível em:<http://www.crda.com.br/tccdoc/22.pdf>.

Sassi, F. (2013). O impacto da deficiência infantil aos pais e o processo de reconhecimento desta realidade por meio do auxílio promovido pelas equipes de profissionais da saúde. RS: Acadêmica do curso de Psicologia da Universidade de Caxias do Sul, Disponível em: <http://www.psicologia.pt/artigos/textos/TL0319.pdf>.

Schimidt, C., Bosa, C. (2007). Estresse e auto-eficácia em mães de pessoas com autismo. Arquivos Brasileiros de Psicologia, v. 59, n. 2, Rio Grande do Sul, Disponível em: $<$ <ttp://pepsic.bvsalud.org/scielo.php?script=sci_arttext\&pid=S180952672007000200008>.

Silva, S.B. (2009). O autismo e as transformações na família. Itajaí- SC: UNIVALI Disponível em:<http://siaibib01.univali.br/pdf/scheila\%20borges\%20da\%20silva.pdf>. 